\title{
A Proposed Model for the Mutual Dependency Between QoE and QoS in Wireless Heterogeneous Networks
}

$\begin{array}{ccc}\text { Hasan F. Khazaal } & \text { Rawaa I. Farhan } & \text { Baraa I. Farhan } \\ \text { Engineering college } & \text { Dentistry college } & \text { Engineering college } \\ \begin{array}{ccc}\text { Wasit University } \\ \text { fh1964@yahoo.com }\end{array} & \begin{array}{c}\text { Wasit University } \\ \text { ralrikabi@ouwasit.edu.iq }\end{array} & \begin{array}{r}\text { Wasit University } \\ \text { bfarhan@ ouwasit.edu.iq }\end{array}\end{array}$

$\begin{array}{ccc}\text { Haider Th. Salim ALRikabi } & \text { Tasos Dagiuklas } & \text { Stavros Kotsopoulos } \\ \text { Engineering college } & \text { South Bank University } & \text { University of Patras } \\ \text { Wasit University } & \text { London } & \text { Greece }\end{array}$

halrikabi@ouwasit.edu.iq

Recived : $14 \backslash 8 \backslash 2017$

Revised : 29\8\2017

Accepted : 7\912017

\begin{abstract}
Streaming of video over wireless heterogeneous networks coping with the problem of packet loss which affects the perceived video quality. The service providers usually use the Peak Signal to Noise Ratio PSNR as a metric measure for the quality of their provided service. So they use the quality of service QoS of the network as a sign on the quality of their presented service. The QoS deal with the objective tests of the provided service, which mean the measure of PSNR of the presented objects. The presented objects may not get the satisfaction of the network users due to many factors although that the PSNR of the used service is enough for presenting the service. Recently the service providers use the Quality of Experience QoE term which deal with the subjective test of the presented object (i.e. the user satisfaction measure). In this paper we propose a new model to identify the importance or the significance of the role of the QoE assessment for the service providers. To verify our proposed model we did a referendum for 55 participants in order to assess their judgment on the quality of some presented videos. The results of the referendum match the consideration of the proposed model.
\end{abstract}

Keywords: QoS, QoE. 


\section{Introduction}

Evolution of telecommunications during the last decades has been enormous [1,2], which leads to an increasing demand for multimedia applications like video over internet protocol (VoIP), Video on Demand (VoD), and data service. These applications are transmitted across various types networks, such as $\mathrm{xDSL}$, WLAN, 3G, 4G etc. The transfer of realtime data over heterogeneous wireless networks is subject to errors of various types which will have an effect on the Quality of Service (QoS) of the networks that affect the Quality of Experience (QoE) [3-6]. The ultimate goal of application services over the networks is to realize the overall acceptability as perceived subjectively by the end user; this means guarantees of QoE. From a layered architectural point of view, QoE is identified as user-level QoS. In practice, the user-level QoS is on the top of application-level QoS [7].

This paper proposes a study that takes the two concepts (QoS \& QoE) in analysis for elucidation of the role of each one of them. aiming to realization of the proposed model and to prove the significance of the role of the QoE.

The rest of the paper is structured as follows: section 2 describing the relationship between QoS \& QoE, section 3 describe the importance of the QoE, section 4 identifies the factors related to QoE, section 5 describes the QoS role as an objective quality assessment, section 6 describes the experiment method and the results, section 7 conclude the results, and finally section 8 is the references.

\section{Relationship between Quality of Service (QoS) and Quality of Experience (QoE).}

"The satisfaction of the people is unreachable destiny". Quality of Service and Quality of Experience are two different concepts. That is QoS from its definition is "the ability of the network to provide a service with an assured service level [8].
Network Services are considered end-to-end; this means from a Terminal Equipment (TE) to another TE. An End-to-End Service may have a certain Quality of Service (QoS), which is provided for the user of a network service. It is the user that decides whether he is satisfied with the provided QoS or not [9].

Unlike QoS, QoE is defined as "The overall acceptability of an application or service, as perceived subjectively by the end-user", or it is the characteristics of the sensations, perceptions, and opinions of people as they interact with their environment. This means that the QoE is more complex concept compared to the QoS. QoE will include the total end-to-end system effects. Moreover, it is influenced each user expectations and context [10,11]. QoS and QoE have mutual dependency, that the service providers use QoE process results to develop QoS, in the same time QoE using QoS as an input to assess the quality of perceived video or audiovisual objects. This process (mutuality) will continue to almost have relatively satisfaction from the user of multimedia services. Nowadays; because of there is an increasing in demand for multimedia services especially audiovisual objects, it is necessary to shift the focus of future services and service design towards the user with its true needs. This has important consequences especially for the notion(s) of service quality. More specifically, the traditional and well-established concept of "Quality-of-Service" (QoS) based on network metrics like bandwidth, loss rate, delay or jitter, has lost its predominance, because it is concern only with the measurable quantities regardless satisfaction. Whereas service design and end user perception are rapidly gaining prominence [12-14] and the attention of the researchers focusing on the relationship between QoS \& QoE in order to strengthening the correlation between them [figure 1], to develop the overall performance of the networks which will reflect on the users' satisfaction [13-17]. So the QoE is a promising method to take into account the users' needs in designing, monitoring and managing networks[18]. 


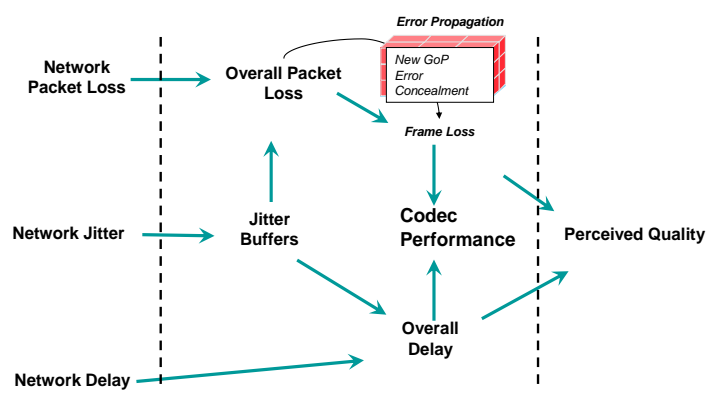

Fig. 1: Correlation between Network QoS and Application QoS.

\section{3 .Quality of Experience (QoE)}

Quality of experience is a concept that it is beyond assessment of the perceived video quality. In communication networks the use of quality of experience as one of the methods that used for assessment of multimedia services like audiovisual subjects, becomes more important and attractive method because it depends on the human, mainly on the human visual and hearing systems, and this is of great interest to judge on the quality of the perceived audiovisual objects, and this judgment used to develop the quality of service (QoS) of the networks. Because of the dependency of this method on the human with all of his psychological and physiological nature, his educational background (level), and his interests and habits, and also the available conditions with surrounding environment at the time of presentation, it is called subjective method. That it is (QoE) affected by these factors either individually or as a result of the interaction between all or some of these factors. So the judgment on the quality of the perceived video will affected if there is a defect in performance in one of these factors. Figure two presents the proposed model of QoE environment structure and its interaction with QoS.

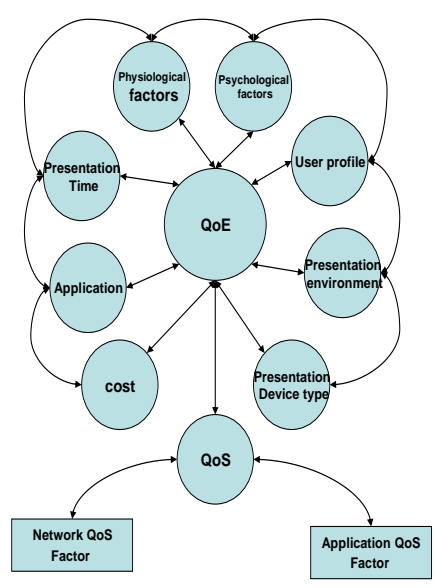

\section{Fig. 2: Quality of Experience environment structure}

There are two faces for assessing the QoE which are:

1- Supervised or Intentional assessment. [12]

2- Unsupervised or unintentional assessment. [13]

In supervised assessment the assessment is done as a supervised referendum, in which the supervisor governing and control all the referendum process elements (choosing the number of participants with all relative factors depend on them, the place of the presentation, the kind of subject of the presented objects, the environments of the presentation, the kind and the size of the presentation device, and the time and the period of the presentation), here the choosing of the elements seems as pseudorandom chooses but it is intentional. The person under this test is called participant, and the results is directed results. It is costly method.

In unsupervised assessment the assessment is done as unsupervised referendum (i. e. Without control or intervention from any one for choosing the kind of elements of the referendum process covering all the previous elements, only the number of persons who participate in this process

is still under control). The participants with all relative factors depend on them are random samples, and the place of the presentation, the kind of subject of the presented objects, the 
environments of the presentation, the kind and the size of the presentation device, the time and the period of the presentation are uncontrolled elements, because this assessment is done in natural conditions and environments. The participants here called user and the results is natural results.

(In the next section there are descriptions in details for all factors that related to QoE).

\section{The Factors Related to QoE}

In the previous section there is an addressing for the factors that have direct effect on judgment on perceived audiovisual objects. These factors are:

- Physiological factor.

- Psychological factor.

- User profile.

- Presentation environment.

- Application

- Presentation time.

- Presentation device type.

- $\quad$ The cost.

\section{- Physiological Factor}

It is an important factor, that related to subjectivity of assessment of the quality of perceived video because it has direct effect on the QoE that it is related to visual and audio systems of the Man. Perceived video usually presented in audiovisual manner, so the participant (user) will make his assessment on the quality of the presented object according to the validation of his visual and hearing systems, that if there is some problem (anatomic problem) like color blindness, astigmatism, myopia (shortsightedness), hyperopia (longsightedness), cochlea infection, weak in hearing nerve or any other problem due to anatomical reasons in these two systems which lead to disturb the perceived video and in a result

make the user judgment in lower level of the score of assessment.

\section{- Psychological Factor:}

This factor plays a key role in assessing the quality of the perceived video, that the assessment depend on the condition of the user psychology, does he is happy or sad or bored or have a bad temper. All of these sub factors will affect the assessment of the user on the quality of the presented object individually or as a result of interaction between them.

\section{- User Profile}

This factor concerning with many sub factors that related with the behaviors of the Man as it is affecting on his behavior like instructional background of the user, his interests, his habits, and his job nature, that the assessment of the user on the presented object will be according to one of these sub factors or as the result of interaction between them (i. e. there is a difference in assessment between the user who have a Ph. D. degree and the user who is Illiterate, also there is a difference in assessment of the users according to differences in their jobs nature like Professors, Doctors, Engineers, Lawyers, Sailors, students (kinds of student), officers, and so on. The assessment will be different if the presented object does not match the interests of the user. Also user tongue (language) has a significant effect on the interaction between the user and presented objects.

\section{- Presentation environment}

The environment of the place of presentation objects have an effect on the assessment of the user, that if the place of the presentation doesn't realized the required condition for presentation like the arrange of the seats or lightening level of the place or the reverberation time of the sound is high which making an echo in sound or if there is some noise due to bad insulation for the walls (acoustical considerations), the angle of viewing the objects and if there is a bad control for the temperature level of the place (depend on the nature of presentation place, i.e. indoor or outdoor presentation). All of these sub factors affecting the judgment on the quality of the presented object individually or as a result of interaction between them. 


\section{- Application:}

the type of the application has an effect on the judgment of the user on the quality of service, because according to the type of the presented object, the QoE will be (e. g. the quality of YouTube presentation object has poorer quality because it is free service and popular comparing with the quality of surgical operation presentation because of its profissionality and importance. Also it differs from the quality of the sports game presentation and so on). So the judgment of the user will have affected by the type of application of presented object.

\section{- Presentation time}

The choose of the suitability of the time for presentation of the audiovisual objects is very important that it must match the user favorites time for using its mobile device to play the videos or movies, to get fair judgment on the presented object.

\section{- Presentation device type:}

the type and the size of the presentation device will affect on the assessment of the user on the quality of the presented object because there is a difference in quality between monitors due to production technology (Plasma, CRT), or due the size of monitors (LCD 62" television monitors, PC or laptop Monitors, Mobile monitors) and also the type of the of the audio system (stereo, mono, etc). All of these sub factors will affect the assessment individually or as a result of interaction between audiovisual systems.

\section{- The Cost:}

The cost of the presentation will affect on the assessment on the quality of the presented object that reducing the number of participants in assessment to reduce the cost of assessment will affect on the result of judgment, or if the choose of place or the type of presentation device is coming according to some economic considerations.
So it must be take all of the preceding factors in consideration to have satisfactory results which led to develop the Quality of Service (QoS) accordingly.

\section{5 .Quality of Service (QoS)}

QoS considered as one of the important factors that the QoE depend on it to assess the presented objects quality, because it is used as an objective assessment by the service providers to assess their services through networks to improve their service according to it. QoS uses the PSNR of the presented objects as an objective metric. PSNR is defined as the logarithmic ratio between the maximum value of a signal and the background noise (MSE) as follows

$$
P S N R=10 \log _{10} \frac{L^{2}}{M S E}
$$

\section{Where}

$\mathrm{L}$ is the maximum luminance value in the frame. When the pixels are represented using 8 bits per sample, $\mathrm{L}=2^{\mathrm{k}}-1$, for $\mathrm{k}=8$ (i.e. 8 bit representation) then $\mathrm{L}=255$

And MSE is the Mean Square Error (MSE) between the original (o) and the distorted (d) versions of a video sequence, and it is calculated as follows:

$$
M S E=\frac{1}{M . N} \sum_{m=1}^{M} \sum_{n=1}^{N}|o(m, n)-d(m, n)|^{2}
$$

Where each frame has $\mathrm{M} \times \mathrm{N}$ pixels, and $\mathrm{o}(\mathrm{m}, \mathrm{n})$ and $\mathrm{d}(\mathrm{m}, \mathrm{n})$ are the luminance pixels in positions $(\mathrm{m}, \mathrm{n})$ of a frame of the sequence. Generally, PSNR and other objective testing are based on computing a sort of distance between input and output sequences, that means, they need the reconstructed video. Thus, they can not be used in real-time [6]. There are two main factors related with QoS, and have a direct effect on it, these two factors are Network QoS factor and Application QoS factor. 


\section{Literature Review}

In [17] the authors present a correlation model between QoE and QoS based on a review study for some previous presented models. This model ties together user perception, expectations, and experience of the application and network performance. In [19] the paper discusses the challenges and a possible solution for optimizing end-to-end QoE in Next Generation Networks. And then the authors propose an E2E QoE assurance system that contains two major components: a QoE/QoS performance reporting component installed at TE, and the QoE management component installed at networks and sources. The QoE/QoS reporting components measure QoE and QoS performances received by users, and then report them to networks and sources. The QoE management components adjust transport functions and reconfigure application-layer parameters to maximize user QoE. The conclusion of this paper is that E2E QoE assurance in an NGN still needs to address many research issues, and will receive intense research attention from both academia and industry, driven by the strong desire to generate revenues and increase the competitiveness of service providers. In [20] the authors presenting a game that relate the olfactory and auditory senses to investigate the influences of them on fairness for a networked virtual 3D object identification game with haptics using subjective test as the assessment for this investigation. In this game they present four scenarios to identify objects which are placed in a shared 3D virtual space, employing two players. Smells and sounds are presented in the first scenario, only sounds are done in the second scenario, and only smells are done in the third scenario. In the last scenario, they present neither smell nor sound. As a result, they conclude that MOS of fairness is large when a pair of subjects is in the same conditions, and it is small when they are in different conditions. Also they noticed that MOS when only smell is presented is smaller than that when only sounds are done. And they illustrated that MOS becomes smaller as the number of different conditions of a pair of subjects becomes larger. In [21] the authors provide a basic principle of QoS of the 4G LTE service. Also they discussed the impact of QoS parameters on QoE such as real-time and
Hasan. F/ Rawaa. I/ Baraa. I/ Haider .Th/Tasos. D/Stavros. K

video communication services. The parameters that have been studied are throughput, latency (delay), jitter (delay variation) and packet errors or loss. The authors conclude that the service provider must provide the costumer a satisfactory service levels for different types of streamed traffic.

It can bee noticed from the presented literatures that the authors focusing on the conditions of the presenting services environment, while they ignoring or have less attention to the users of service own conditions and the interaction between the users own conditions and the surrounding environments. So the aim of this paper is to present a comprehensive model that could be identify the interaction between all the parameters that have an effect on the judgment on the service quality by the user itself.

\section{Experiment and results}

In order to verify the proposed model, the experiment passes through some steps,

- $\mathbf{1}^{\text {st }}$ step: in this step; two groups of videos are streamed over wireless channel using IEEE 802.11 wireless channel which modeled as two state GilbertElliot model [22] through simulation scenario with conditioned network environment to have some effects on the streamed videos to make the network environment as the real network as possible using network simulator NS2 [23]. each group of videos contains three videos of the same quality, each video within the group suffered from different channel effects to make the re-constructed videos have different quality from the other videos. The first group of videos contains three videos of same quality; each video suffered from such effects. The second group contains three videos also, and it is simulated as of the first group with the same environment and conditions but with different effects to make them have scene differs from the first group of videos. The streamed videos used, named "coastguard_CIF.yuv " of 300 frames, and 10 second duration time. All video sequences have been encoded using H.264 test model software encoder $[24,25]$. 
$2^{\text {nd }}$ step: in this step the received videos of the two groups are reconstructing after simulation to calculate the PSNR for each reconstructed video (i.e. metric calculation of objective test). See figure 3 for the procedure of simulation and figure 4, 5 for PSNR results of the group 1 videos and group 2 videos respectively.

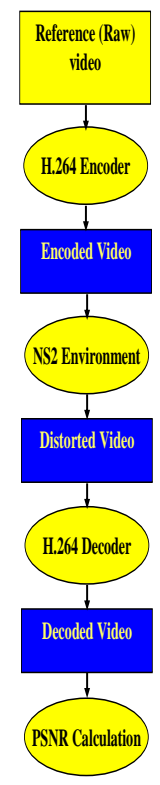

Fig. 3: The procedure of simulation

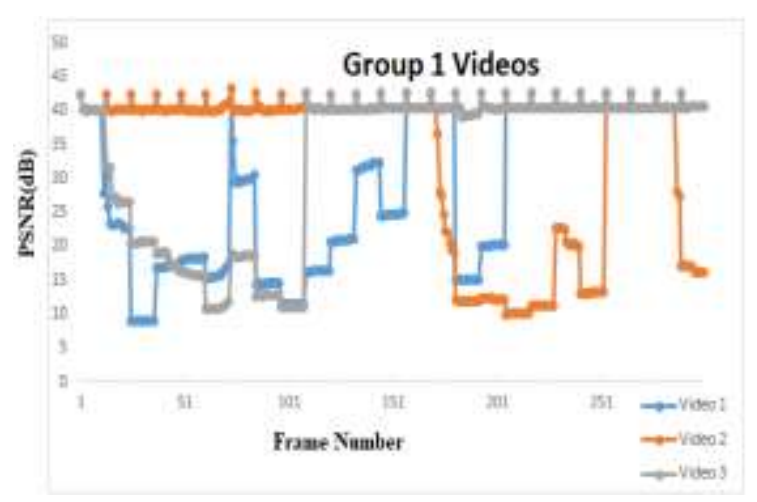

Fig. 4: PSNR results for Group 1 Videos

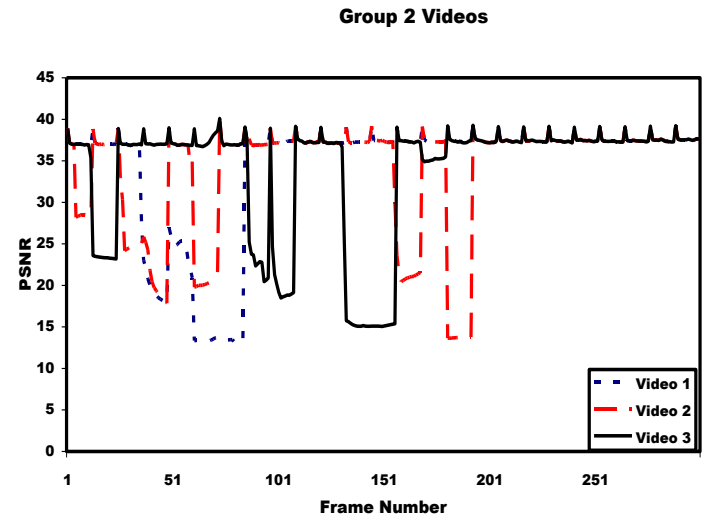

Fig. 5: PSNR results for Group 2 Videos

- $3^{\text {rd }}$ step: this step is the the step of subjective assessment. In this step the two groups of reconstructed videos were presented for voting to assess its quality by a subjective test. The first group of reconstructed three videos is presented with original video to 55 participants who were grouped into sub groups with different size (i.e each group contains 2 to 5 participants). These groups of participants are mixed from males and females with ages from 18 to 55 years old, and have different life experiences, scientific qualification, jobs, and cultures; also no one of them has knowledge about video coding. The presented videos were displayed by 17 " monitor of laptop, with well conditioned places environments (i.e. suitable light illumination, suitable room temperature, comfortable seats, and suitable viewing angle with the all considerations that give the participants the comfortable situation to give suitable judgment on the presented videos). The presented videos were repeated five times before starting the test to prepare the participants for assessment test in other words, to make the participants familiar with the test at which the presented videos group is displayed five times again to give the participants clear view for comparison between the three videos and then issue their judgment on perceived video quality. After each judgment or voting on the first group of videos the participants get a rest time of duration of 10 minutes, and then the second group of videos is presenting to the same group of participants with the same procedure of presenting the first group of videos in order to 
check if the participants voting comes from fully convinced for the perceived video quality. Now someone says why the referendum done in this method? The answer to this question comes from the proposed model, that the referendum must achieve all the items of the model with the consideration of the time (not the period) of presentation weather suitable for the referendum participants or not, in order to give the referendum more unintentional matter.

- $4^{\text {th }}$ step; in this step the collected data from the two tests of third step is processed to calculate the Mean Opinion Score (MOS) in order to compare the results of MOS with the results collected from the second step (PSNR results). The common opinion scores are as indicated in table 1.

Table 1: Mean Opinion Score - MOS

\begin{tabular}{|l|l|l|l|}
\hline Score & Quality & PSNR & Impairment \\
\hline 5 & Excellent & $>37$ & Imperceptible \\
\hline 4 & Good & $\mathbf{3 1 - 3 7}$ & $\begin{array}{l}\text { Perceptible } \\
\text { but not } \\
\text { annoying }\end{array}$ \\
\hline 3 & Fair & $\mathbf{2 5 - 3 1}$ & $\begin{array}{l}\text { Slightly } \\
\text { annoying }\end{array}$ \\
\hline 2 & Poor & $\mathbf{2 0 - 2 5}$ & Annoying \\
\hline 1 & Bad & $<20$ & $\begin{array}{l}\text { Very } \\
\text { annoying }\end{array}$ \\
\hline
\end{tabular}

- $5^{\text {th }}$ step; in this step the results of PSNR and MOS are tabulated in table 2 to make the comparison between them.
Table 2: MOS \& PSNR results

\begin{tabular}{|c|c|c|c|}
\hline & $\begin{array}{c}\text { Video } \\
\text { number }\end{array}$ & MOS & PSNR \\
\hline \multirow{3}{*}{ 总 - } & 1 & 1.818 & 32.96 Good \\
\hline & 2 & 1.382 & 28.6 Fair \\
\hline & 3 & 1.927 & 32.4 Good \\
\hline \multirow{3}{*}{ 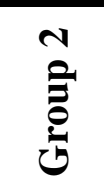 } & 1 & 1.745 & 34.24 Good \\
\hline & 2 & 2 & 33.79 Good \\
\hline & 3 & 1.927 & 33.81 Good \\
\hline
\end{tabular}

From the indicated results in table 2, it can be noticed that the scores of the subjective test of group 1 videos does not tune with the results of objective tests by means of PSNR (theoretically the highest PSNR must have highest MOS). But here the result comes as we expect in the proposed model, that the satisfaction of the network user is not necessarily matches the objective metric or PSNR results of the network service. That is why the subjective test on the second group of videos comes on. It is to reinforce the idea of the proposed model. The results of this test (group 2 test) indicated that MOS of the presented videos also dose not match the scores of PSNR of the objective test So the MOS of the two subjective tests comes with low level scores although the PSNR results have Good level, and this level must match theoretically the score " 4 " in MOS ladder.

\section{Conclusions}

We said earlier that the satisfaction of the people is unreachable destiny. But these words need to be proved by such matter, so we propose the model that gives a comprehensive idea on the factors that have an effect on the satisfaction of the users' of networks services keeping in mind all the consideration of the importance of each factor. The QoE comes in the heart of this model. So, what is the idea or the wisdom behind the putting of the QoE factor in the core of this model is the orientation of this research. The research start with 2 tests and each test have two parts 
(objective test and subjective test) to collect the data to be compared with each other. The comparison between MOS and PSNR results of the first test comes as we expect that it matches the most important idea behind this model (i.e. the QoE with all of its factors is more important than the QoS) that MOS consider as the user satisfaction on the network services. But this result must be reinforced by another test. So we did the second test. Also the results of the second test indicate that the MOS of the subjective test dose not depend on the PSNR of the presented object, and it does not match the theoretical level of PSNR (this is clear when comparing the results of Video No.1 of the second group by means of MOS \& PSNR, that although the PSNR of video No. 1 is the highest value among the six videos, it has the least MOS score among them i.e. the least participants satisfaction). The results of the two tests prove that the use of MOS as new criteria for the service quality will improve the network services quality, because it is reflecting the user satisfaction which is considered as the destiny of the networks services providers.

\section{REFERENCES}

[1] Charilas D., Markaki O., Nikitopoulos D. , Theologou M., "Packet-switched network selection with the highest QoS in

4G networks", Computer Networks, Vol 52, pp. 248-258, 2008.

[2] Markaki O., Charilas D. , Nikitopoulos D.,"Enhamcing Quality of Experience in Next Generation Networks Through Network Selection", IEEE $18^{\text {th }}$ Annual International symposium on Personal, Indoor, and Mobile Radio Communications (PIMRC'07), 2007.

[3] Suzuki T., Kutsuma T., Tasaka S., "QoE Estimation from MAC-Level QoS in Audio-Video Transmission with IEEE 802.11e EDCA", IEEE $19^{\text {th }}$ International Symposium on Personal. Indoor and Mobile Radio Communications 2008 PIMRC, Sept. 2008.

[4] Kim H.-J. , Lee D.-H., Lee J.-M., Lee K.-H., Won Lyu W., Choi S.-G., "The QoE Evaluation Method through the QoS-QoE Correlation Model", Fourth International Conference on Networked Computing and Advanced Information Management NCM'08, Vol.2, pp. 719-725, Sept 2008.
[5] Latr'e S., Simoens P., De Vleeschauwer B., Van de Meerssche W., De Turck F., Dhoedt B., Demeester P., Van Den Berghe S., de Lumley E. G., "Design for a generic knowledge base for autonomic QoE optimization in multimedia access networks", IEEE Symposium workshops on Networks Operations and Management NOMS '08, pp.335-342, April 2008.

[6] Ghareeb M., Viho C., "Hybrid QoE is Well-Suited for Multiple Description Coding Video Streaming in Overlay Networks", IEEE Proceedings of Eighth Annual conference on Communication Networks and Services Research (CNSR), pp. 327-333, May 2010

[7] Tasaka S., Yoshimi H., "Enhancement of QoE in Audio-Video IP Transmission by Utilizing Tradeoff between Spatial and Temporal Quality for Video Packet Loss", IEEE Proceedings of the Global Communications Conference, 2008. GLOBECOM 2008, pp.1426-1431, New Orleans, LA, USA, Nov. - Dec. 2008.

[8] Gardiner B "QoS: What is it? Why we need it?", white paper, Nokia Corporation April 2008.

[9] 3rd Generation Partnership Project; Technical Specification Group Services and System Aspects, (Release 4), "QoS Concept and Architecture",3GPP TS 23.107 V.4.4.0 (2002-03).

[10] Kishigami J., "The Role of QoE on IPTV Services",IEEE 9th International Symposium on Multimedia, ISM, '07, pp. 11-13, Dec.2007.

[11] Arun Kumar P. M.; Chandramathi S., "Intelligent Video QoE Prediction Model for Error-prone Networks", Indian Journal of Science and Technology (ijst), Vol. 8 issue 16, July 2015

[12] Reichl P., "From 'Quality-of-Service' and 'Quality-ofDesign' to 'Quality-of-Experience': A Holistic View on Future Interactive Telecommunication Services", $15^{\text {th }}$ International conference on Software,Telecommunictions and Computer Networks (SoftCOM), Sept. 2007.

[13] Jain R., "Improving quality of service for streaming multimedia applications in ubiquitous mobile environment", ACM Proceedings of the 43rd annual Regional Conference, Vol. 2, pp. 14-19, Kennesaw, Georgia, 2005. 
[14] Latr'e S., Simoens P., De Vleeschauwer B., Van de Meerssche W., De Turck F., Dhoedt B., Demeester P., Van Den Berghe S., de Lumley E. G.,., "An autonomic architecture for optimizing QoE in multimedia access networks", Computer Networks, Vol. 53, pp. 1587-1602, 2009.

[15] Escudero-Garzás J. J. and Bousoño-Calzón C., "An Analysis of the Network Selection Problem for Heterogeneous Environments with User-Operator Joint Satisfaction and Multi-RAT Transmission", Hindawi Wireless Communications and Mobile Computing, Volume 2017(2017), Article ID 7425412, 13 pages.

[16] Wang Z. ; Li L.; Wang W. ; Wan Z. ; Fang Y. ; Cai C., "A study on QoS/QoE correlation model in wireless-network", Proceeding of Annual Summit and Conference of Asia-Pacific on Signal and Information Processing Association (APSIPA), 2014.

[17] Alreshoodi M., Woods J.," Survey on QoE/QoS Correlation Models for Multimedia Services", International Journal of Distributed and Parallel Systems (IJDPS) Vol.4, No.3, May 2013.

[18] Msakni H. G.; Youssef H., "Is QoE estimation based on QoS parameters sufficient for video quality assessment?", Proceeding of $9^{\text {th }}$ International Conference on Wireless Communications and Mobile Computing (IWCMC), 2013.

[19] Zhang J., Ansari N., " On Assuring End-toEnd QoE in Next Generation Networks: Challenges and a Possible Solution", IEEE Communications Magazine, pp. 185-191, July 2011.
Hasan. F/ Rawaa. I/ Baraa. I/ Haider .Th/Tasos. D/Stavros. K

[20] Arima R., Sithu M., Ishibashi U., " QoE Assessment of Fairness between Players in Networked Virtual 3D Objects Identification Game Using Haptic, Olfactory, and Auditory Senses", SCIRP; Int. J. for Communications, Network and System Sciences, Issue 10, pp. 129-141, 2017.

[21]Malisuwan S., Milindavanij D., Kaewphanuekrungsi W., " Quality of Service (QoS) and Quality of Experience (QoE) of the 4G LTE Perspective", International Journal of Future Computer and Communication, Vol. 5, No. 3, pp. 158-162, June 2016.

[22] Chen L.-J., Hung H.-H., "A Two-State Markov-Based wireless Error Model for Bluetooth Networks", Springer Science+Business Media, Wireless Personal Communication, Issue 58, pp. 657-668, 2011

[23] The Network Simulator NS-2., http://www.isi.edu/nsnam/ns/. 2011 online

[24] YUV Video Sequences, Arizona State University, 2009.

http://trace.eas.asu.edu/yuv/index.html.

[25] Fraunhofer Heinrich Hertz Institute HHI, 2009. http://ip.hhi.de 
نموذج مقترح للاعتماد المتبادل بين جودة التجربة وجودة الخدمة في الثبكات اللاسلكية الغير المتجانسة النجة

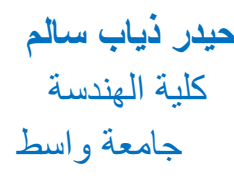

جلية الهندسة ذياب سالم

$$
\begin{gathered}
\text { ستافروس كوتسوبولوس باتزر اليونان } \\
\text { جامسون }
\end{gathered}
$$

$$
\begin{gathered}
\text { براء اسماعيل فرحان الهندسة } \\
\text { جامعة واسط }
\end{gathered}
$$

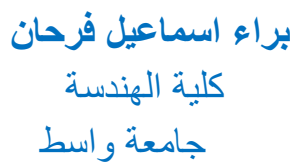

$$
\text { حسن فهلة الهندسة }
$$

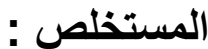

بث الفيديو عبر الثبكات اللاسلكية يتعامل مع مشكلة خسارة الحزمة التى تؤثر على الاحساس بجودة الفيديو . عادة ما يستخدم مقدمو الخدمة نسبة اشارة الذروة إلى الضوضاء (PSNR) كمقياس منري لنوعية الخدمة المقدمة لهم. لذلك فهي تستخدم جودة الخدمة QoS من الثبكة كعلامة على نوعية الخدمة

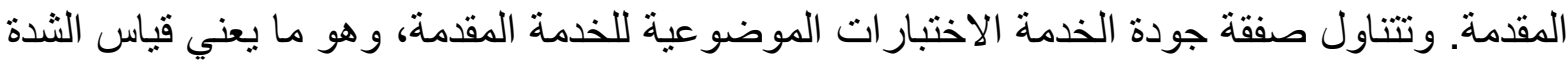
للأشياء المعروضة. وقد لا تحصل الأجسام المعروضة على الأى رضا مستخدمي الثبكة بسبب (PSNR) عو امل كثيرة على الرغم من أن نسبة الإشارة إلى الضوضاء (PSNR) للخدمة المستعملة تكفي لتقديم الخدمة. وفى الاونة الاخيرة، يستخدم موفرو الخدمة المصطلح QoE جودة الخبرة التى تتناول اختبار ذاتى للكائن المقدمة (أي قياس رضا الإنس المستخدم). فى هذه الورقة نقترح نموذجا جديدا لتحديد اهميتها او اهمية دور QoE التقييم لمقدمى هذه الخدمات. للتحقق من نموذجنا المقترح قمنا بإجر اء استفتاء ل 55 مشاركا لتقييم حكمهم على جودة بعض أشرطة الفيديو المقدمة. نتائج الاستفتاء تطابقت مع اعتبار ات

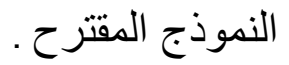

